Jurnal Sastra Indonesia

http://journal.unnes.ac.id/sju/index.php/jsi

\title{
KRITIK SOSIAL DALAM NASKAH DRAMA OBROG OWOK-OWOK EBREG EWEK-EWEK KARYA DANARTO: TINJAUAN SOSIOLOGI SASTRA
}

\section{Zaenudin $^{\bowtie}$, Mulyono}

Jurusan Bahasa dan Sastra Indonesia, Fakultas Bahasa dan Seni, Universitas Negeri Semarang, Indonesia

\section{Info Artikel}

Sejarah Artikel:

Diterima April 2018

Disetujui Juli 2018

Dipublikasikan November 2018

\section{Keywords:}

social criticism, play script, sociology of literature

\begin{abstract}
Abstrak
Naskah drama Obrog Owok-owok Ebreg Ewek-ewek karya Danarto dipilih untuk dikaji karena di dalam naskah drama ini terdapat berbagai masalah sosial yang kemudian memunculkan kritik. Kritik-kritik yang terdapat dalam naskah drama tersebut perlu dikaji dan disampaikan ke publik. Naskah drama ini juga memiliki keunikan. Dialog yang sama diucapkan dua atau tiga tokoh berurutan bahkan hampir bersamaan, namun tidak dalam satu ruang dan waktu. Naskah drama ini seolah-olah mencoba untuk menyatukan dimensi ruang dan waktu. Naskah drama ini adalah naskah dengan struktur yang tidak dapat dikatakan sederhana, meskipun secara umum termasuk dalam naskah realis. Tujuan penelitian ini adalah mendeskripsikan kritik sosial yang terdapat dalam naskah drama dan mendeskripsikan wujud ekspresi kritik sosial tersebut membangun estetika drama dalam naskah Obrog Owok-owok Ebreg Ewek-ewek karya Danarto.
\end{abstract}

\section{Abstract}

The play script of Obrog Owok-owok Ebreg Ewek-ewek by Danarto is chosen to be studied because in this play script there are various social problems which then generate criticism. The criticisms contained in this play script need to be reviewed and submitted to the public. This play script also has uniqueness in the dialogue. The same dialogue is spoken by two or three characters in sequence even almost simultaneously, but not in the same place and time. It looks as if trying to unify the dimensions of space and time. This play script is a text with a structure that cannot be said to be ordinary, although it is generally classified as realist script. Furthermore, in this drama script there are various social problems which then led to criticism. The purpose of this study is to describe the social criticism contained in the play script and describes form expression of social criticism build the aesthetic of drama in Obrog Owok-owok Ebreg Ewek-ewek by Danarto.

(C) 2018 Universitas Negeri Semarang

\footnotetext{
Alamat korespondensi:

Gedung B1 Lantai 1 FBS Unnes

Kampus Sekaran, Gunungpati, Semarang, 50229

E-mail: zaenudinumardi@gmail.com
}

ISSN 2252-6315 


\section{PENDAHULUAN}

Karya sastra menampilkan gambaran kehidupan, dan kehidupan itu adalah suatu kenyataan sosial dan kritik sosial. Kritik sosial dalam karya sastra merupakan upaya yang dilakukan seorang pengarang dengan cara memberikan suatu tanggapan terhadap persoalanpersoalan yang ia lihat pada masyarakat. Salah satu karya sastra yang merefleksikan kehidupan manusia dengan konflik yang disuguhkan kepada penonton untuk diambil nilai positifnya adalah drama. Drama adalah salah satu karya sastra yang bersifat dialog dan isinya membentangkan sebuah alur. Drama itu berbeda dengan prosa dan puisi, karena drama dimaksudkan untuk dipentaskan.

Naskah drama Obrog Owok-owok Ebreg Ewek-ewek karya Danarto dipilih untuk dikaji karena di dalam naskah drama ini terdapat berbagai masalah sosial yang kemudian memunculkan kritik. Kritik-kritik yang terdapat dalam naskah drama tersebut perlu dikaji dan disampaikan ke publik. Naskah drama ini juga memiliki keunikan. Dialog yang sama diucapkan dua atau tiga tokoh berurutan bahkan hampir bersamaan, namun tidak dalam satu ruang dan waktu. Naskah drama ini seolah-olah mencoba untuk menyatukan dimensi ruang dan waktu. Naskah drama ini adalah naskah dengan struktur yang tidak dapat dikatakan sederhana, meskipun secara umum termasuk dalam naskah realis. Tujuan penelitian ini adalah mendeskripsikan kritik sosial yang terdapat dalam naskah drama dan mendeskripsikan wujud ekspresi kritik sosial tersebut membangun estetika drama dalam naskah Obrog Owok-owok Ebreg Ewek-ewek karya Danarto.

Dalam penelitian ini, teori-teori yang digunakan sebagai berikut.

Hakikat Drama

Soemanto (dalam Dewojati 2012:7), berpendapat bahwa istilah tersebut mengacu pada drame, sebuah kata dari bahasa Perancis yang diambil oleh Diderot dan Beumarchaid untuk menjelaskan lakon-lakon mereka tentang kehidupan kelas menengah. Oleh karena itu, drama dapat diartikan sebagai perbuatan atau tindakan. Selain itu Harymawan (1988:1), mengartikan drama sebagai cerita konflik manusia dalam bentuk dialog yang diproyeksikan pada pentas dengan menggunakan percakapan dan action di depan penonton. Sejalan dengan pendapat itu, Ferdinand dan Balthaza Verhagen (dalam Hasanuddin 1996:3) mengemukakan bahwa drama merupakan kesenian yang melukistan sifat dan sikap manusia dan harus melahirkan kehendak manusia dengan action dan perilaku.

\section{Kritik Sosial}

Ratna (2004: 119) menjelaskan bahwa kritik sosial termasuk dalam ilmu sastra, pada umumnya memperoleh masukan melalui sudut pandang Marxis, bahwa ide, konsep dan pandangan dunia individu ditentukan oleh keberadaan sosialnya. Kenyataan yang demikian dibangun secara sosial, kenyataan dengan kualitas mandiri yang tak tergantung dari kehendak subjek.

Kritik sosial juga dapat berarti sebuah inovasi sosial. Dalam arti bahwa kritik sosial menjadi sarana komunikasi gagasan-gagasan baru sembari menilai gagasan lama untuk perubahan sosial. Dengan adanya kritik sosial diharapkan terjadi perubahan sosial ke arah yang lebih baik. Kritik sosial sebaiknya bersifat kritik yang membangun sehingga tidak hanya berisi kecaman, celaan, atau tanggapan terhadap situasi, tindakan seseorang atau kelompok. Hal ini diperlukan agar kritik sosial tidak menimbulkan permusuhan dan konflik sosial.

\section{Jenis-jenis Kritik Sosial}

Kritik sosial yang menjadi perhatian peneliti dalam penelitian ini dikategorikan kedalam beberapa aspek, yakni kritik sosial masalah ekonomi, politik, sosial-budaya, moral, kemanusiaan, agama atau kepercayaan, dan pendidikan.

\section{Kritik Sosial dalam Sastra}

Damono (1984: 11) menjelaskan bahwa karya sastra dapat menampilkan gambaran kehidupan masyarakat. Berbagai hal atau peristiwa dalam masyarakat dapat memengaruhi pikiran pengarang atau mengendap dalam pikirannya sehingga lahirlah sebuah karya. Sastra dengan ini berarti tidak dapat dipisahkan dari masyarakat. Dalam karya sastra tercermin gambaran tentang struktur sosial, hubungan kekeluargaan, pertentangan kelas, dan lain-lain.

Sementara itu, menurut Sikana (2006: 400-404), karya sastra merupakan sebuah cerminan masyarakat, sebuah dokumentasi sosial, dan sebuah wadah bagi protes sosial. Pada bagian lain dikatakannya pula bahwa teks sastra dapat dianalisis dalam kaitannya dengan isu politik, ekonomi, budaya, dan aspek-aspek lainnya yang membangun masyarakat (Sikana 2006: 397). Halhal yang bisa digali dalam sebuah karya sastra jika sebuah penelitian menggunakan pendekatan sosiologi sastra seperti ekonomi, isu politik, dan budaya.

\section{Sosiologi Sastra}

Karya sastra biasanya berisi lukisan yang jelas tentang suatu tempat dalam suatu masa dengan berbagai tindakan manusia. Manusia dengan berbagai tindakannya di dalam masyarakat 
merupakan objek kajian sosiologi. Marx (dalam Faruk 1999:6), mengatakan bahwa struktur sosial sustu masyarakat, juga struktur lembagalembaganya, moralitasnya, agamanya, dan kesusastraannya, terutama sekali ditentukan oleh kondisi-kondisi kehidupan, khususnya kondisikondisi produktif kehidupan masyarakat itu.

Sastra berhubungan dengan manusia dalam masyarakat termasuk di dalamnya usaha manusia untuk menyesuaikan diri dan usahanya untuk mengubah masyarakat itu. Sesungguhnya sosiologi dan sastra berbagi masalah yang sama. Keterkaitan karya sastra dengan masyarakat biasa disebut dengan sosiologi sastra. Sosiologi dapat memberikan penjelasan yang bermanfaat tentang sastra dan bahkan tanpa sosiologi pemahaman tentang sastra belum lengkap (Damono 1984:2).

\section{Estetika dalam Sastra}

Secara etimologis, estetika berasal dari kata Yunani "aisthetis", "pengamatan" adalah cabang filsafat yang berbicara tentang keindahan. Dalam pengalaman atas dunia sekeliling kita ditemukan suatu bidang yang disebut "indah". Istilah estetika sangat dekat dan erat hubungannya dengan kata seni. Estetika sering dihubungakan dengan sesuatu yang berbau seni karena mengandung keindahan yang dapat dipandang. Djelantik (2004:7) mengemukakan bahwa ilmu estetika merupakan ilmu yang berkaitan dengan keindahan, mempelajari semua aspek dari apa yang kita sebut keindahan.

Pengalaman akan keindahan merupakan objek dari estetika. Dalam estetika dicari "hakikat" dari "keindahan", bentuk-bentuk pengalaman keindahan (seperti keindahan jasmani dan keindahan rohani, keindahan alam dan keindahan seni) dan diselidiki emosi-emosi manusia sebagai reaksi terhadap yang indah, yang agung, yang tragis, yang bagus, yang mengharukan dan seterusnya (Sugiarti, 1999:73). Dalam pengertian yang luas, estetika berarti kepekaan untuk menanggapi suatu objek kemampuan pencerapan indra sebagai sensitivitas dalam bentuk keindahan.

\section{METODE PENELITIAN}

Jenis penelitian yang digunakan adalah penelitian deskriptif kualitatif dengan pendekatan sosiologis. Sasaran penelitian ini adalah mendeskripsikan kritik sosial yang terdapat dalam naskah drama dan mendeskripsikan bentuk ekspresi kritik sosial tersebut membangun estetika drama dalam Obrog Owok-owok Ebreg Ewek-ewek karya Danarto. Dalam penelitian ini, peneliti menggunakan naskah drama Obrog Owok-owok Ebreg Ewek-ewek karya Danarto cetakan pertama, Maret 2014 sebagai sumber data. Data penelitian ini diperoleh dengan menganalisis isi naskah drama Obrog Owok-owok Ebreg Ewek-ewek karya Danarto.

\section{HASIL PENELITIAN DAN PEMBAHASAN}

Kritik Sosial dalam Naskah Drama Obrog Owok-owok Ebreg Ewek-ewek Karya Danarto

\section{Kritik Sosial Masalah Ekonomi}

Kritik sosial masalah ekonomi dalam naskah drama Obrog Owok-owok Ebreg Ewekewek karya Danarto yaitu penilaian kreativitas karya seseorang sangat rendah sehingga nilai ekonomisnya juga rendah. Pada halaman 5-6 naskah drama tersebut, Profesor menganggap desain batik Tommy terlihat biasa saja. Penghargaan terhadap desain batik dan judul batik mampu meningkatkan nilai jual lebih baik. Walaupun demikian, judul batik harus sesuai dengan desain, sehingga orang yang menguasai di bidang tersebut mampu menilai harga ekonomisnya.

Kritik sosial masalah ekonomi selanjutnya yaitu keuntungan ekonomi mulai dari desainer (kreator), konsumen, maupun produsen demi utuhnya jalinan persaudaraan. Pada halaman 28-30, Profesor menyampaikan bahwa walapun berbeda-beda bentuk dan warnanya, pada hakikatnya untuk pemenuhan kebutuhan yang belum memadai harus diterima secara terbuka dan wajar bagi para kreator, konsumen, maupun produsen demi utuhnya jalinan persaudaraan.

Berdasarkan teks naskah drama Obrog Owok-owok Ebreg Ewek-ewek karya Danarto, dapat disimpulkan bahwa terdapat kritik sosial masalah ekonomi yaitu mengenai penilaian ekonomi yang tidak sebanding dengan kreativitas, pengeluaran kebutuhan ekonomi yang tidak sebanding dengan pendapatan, dan keuntungan ekonomi para pelaku usaha.

\section{Kritik Sosial Masalah Politik}

Kritik sosial masalah politik dalam naskah drama Obrog Owok-owok Ebreg Ewekewek karya Danarto yaitu kritik terhadap pemerintah untuk memperhatikan usaha batik agar berkembang dengan pesat. Pada halaman 15-16 naskah tersebut, Tommy telah berusaha keras untuk menciptakan motif-motif baru dan warnawarna baru, dan tidak jarang mendapat kritikankritikan dari Pak Suryo, Ibu Dibyo, dan Marie mestinya juga berusaha keras untuk membuat kritik-kritik yang lain dan lebih maju dari yang sudah-sudah, haruslah mendapat dukungan dari pemerintah desa, daerah, bahkan hingga pusat.

Kritik sosial masalah politik selanjutnya yaitu kritik terhadap pemerintah melalui sindiran Slentem terhadap Undang-undang mengenai 
kesejahteraan bagi rakyat kecil, terutama pengamen. Pada halaman 67-68, Slentem berpendapat bahwa setiap orang berhak mengamen dimana saja dan kapan saja, sebab pada hakikatnya mengamen adalah soal insting dan derajatnya sama dengan pengamen lainnya. Untuk menjaga tata tertib pengamen, Slentem membuat aturan agar tidak terjadi suatu perselisihan yang mengeruhkan suasana antar pengamen.

Berdasarkan teks naskah drama Obrog Owok-owok Ebreg Ewek-ewek karya Danarto, dapat disimpulkan bahwa terdapat kritik sosial masalah politik yaitu kritik terhadap pemerintahan tentang kesejahteraan masyarakat, kritik terhadap pemerintah agar memperhatikan dan mendukung usaha batik agar berkembang dengan pesat, dan kritik mengenai Undang-undang tentang kesejahteraan bagi rakyat kecil, terutama pengamen.

\section{Kritik Sosial Masalah Sosial-Budaya}

Kritik sosial masalah sosial budaya dalam naskah drama Obrog Owok-owok Ebreg Ewek-ewek karya Danarto terjadi ketika Slentem tidak mau mengakui kebenaran mengenai hubungan Tommy dan Kusningtyas. Pada halaman 9-11 naskah drama tersebut, Slentem tidak mau menceritakan semua hubungan Tommy dan Kusningtyas kepada Ati saat didesak pertanyaan, apalagi kepada orang-orang pasar. Hal tersebut dapat menjadikan permasalahan semakin berlarutlarut, membuat resah, dan suasana menjadi panas. Dalam kehidupan sosial budaya masyarakat, seseorang cenderung menutupi kejelekan orang lain demi sebuah kepentingan diri sendiri dan orang lain.

Kritik sosial masalah sosial budaya berikutnya adalah karena anggapan Sumirah terhadap gelar mampu menghasilkan uang untuk kehidupan sosial yang lebih baik. Pada halaman 59-60 Sumirah menganggap seseorang yang memiliki titel mampu menghasilkan uang, tenar, dan mampu mengkat derajat keluarga. Walaupun demikian, Sumirah merasa seseorang yang ingin mendapatkan titel harus mengeluarkan uang yang besar untuk menghasilkan uang yang besar pula.

Kritik sosial masalah sosial budaya berikutnya dalam naskah drama Obrog Owokowok Ebreg Ewek-ewek karya Danarto karena Penamaan batik oleh Tommy yang kurang sesuai. Pada halaman 3-5 Tommy memberi nama batiknya dengan nama "Shadow of Your Smile" tentu mengandung maksud untuk membuat batiknya dapat diterima di dunia internasional, bukan hanya di Indonesia saja. Hal tersebut berbanding dengan pendapat Profesor, dosen Tommy. Menurut Profesor, jika penamaan untuk batik-batik tidak direm bisa berpengaruh terhadap Hollywood yang akan bangkrut judul. Namun lebih dari itu, Profesor menganggap penamaan "Shadow of Your Smile" tidak lazim digunakan sebagai nama batik di Indonesia, terutama di Jawa. Penamaan batik dengan bahasa asing, akan menghilangkan cita rasa khas batik Indonesia. Bagaimanapun juga batik-batik di Indonesia adalah bentuk budaya bangsa, jadi penamaannya pun harus sesuai dengan lingkungannya. Tommy yang memberi nama batiknya dengan menggunakan bahasa asing, tentu bisa membunuh jati diri bangsanya sendiri yang memegang erat budaya yang ada.

Berdasarkan naskah drama Obrog Owokowok Ebreg Ewek-ewek karya Danarto, dapat disimpulkan bahwa terdapat kritik sosial masalah sosial budaya yaitu menjaga solidaritas demi terciptanya kehidupan yang damai dan anggapan gelar demi kehidupan sosial yang lebih baik. Seperti Sumirah mendesak Slentem untuk mengakui kebenaran mengenai hubungan Tommy dan Kusningtyas demi kebaikan bersama, Ati memberikan pengertian kepada Sumirah mengenai kecurigaan hubungan Tommy dan Kusningtyas, persaingan mengamen antara Sariyem dan Warti, anggapan Sumirah terhadap gelar pendidikan mampu menghasilkan uang untuk kehidupan sosial yang lebih baik, dan penamaan batik oleh Tommy yang kurang sesuai.

\section{Kritik Sosial Masalah Moral}

Kritik sosial masalah moral selanjutnya dalam naskah drama Obrog Owok-owok Ebreg Ewek-ewek karya Danarto yaitu Warti menyimpan dendam kepada Sariyem mulai dari perempatan jalan Gayam, Gampingan, hingga pasar Beringharjo. Pada halaman 21-22 naskah drama tersebut, Sariyem merasa tersaingi Warti dalam mengamen di pasar Beringharjo. Mereka dahulunya teman, kemudian terjadi peristiwa pertengkaran. Warti pun menganggap Sariyem dulu memang teman sekolah, tapi sekarang mereka saingan. Warti seakan memancing emosi Sariyem karena dia kesal sebagai balasan peristiwa di sepanjang perempatan jalan Gayam, Gampingan, hingga pasar Beringharjo. Perilaku balas dendam Warti mengenai peristiwa masa lalu merupakan perilaku yang tidak mencerminkan nilai moral.

Kritik sosial masalah moral selanjutnya yaitu Tommy berbohong dan menjanjikan batik kepada Kusningtyas yang tidak pernah ditepati. Pada halaman 32-33, Tommy berusaha meminta ijin untuk meminjam dulu batik tersebut dua tiga hari untuk dibawa ke Jakarta karena ada seorang kolektor yang ingin melihat. Padahal hal tersebut tidak pernah dilakukan Tommy. Perilaku Tommy yang mengumbar janji kepada siapapun merupakan perilaku yang tidak mencerminkan nilai moral. 
Berdasarkan naskah drama Obrog Owokowok Ebreg Ewek-ewek karya Danarto, dapat disimpulkan bahwa terdapat kritik sosial masalah moral yaitu menuduh seseorang tanpa disetai bukti, menebar ancaman terhadap seseorang, berperilaku sombong, menyimpan dendam, selalu menebar janji, berkata kasar, dan menipu. Seperti Profesor menuduh Slentem dengan sewenangwenang karena belum disertakan bukti, Sumirah mendesak Slentem untuk mengakui kebenaran mengenai hubungan Tommy dan Kusningtyas yang disertai ancaman, Slentem mengancam Profesor dengan surat kaleng, Slentem berlagak sombong dan meminta jatah rokok kepada Tommy agar rahasianya tetap terjaga, Warti menyimpan dendam kepada Sariyem mulai dari perempatan jalan Gayam, Gampingan, hingga pasar Beringharjo, Tommy berbohong dan menjanjikan batik kepada Kusningtyas yang tidak pernah ditepati, memberikan sebutan kepada seseorang dengan sebutan binatang, dan Slentem menipu dengan berpura-pura menjadi dukun untuk mendapatkan uang.

\section{Kritik Sosial Masalah Kemanusiaan}

Kritik sosial masalah kemanusiaan dalam naskah drama Obrog Owok-owok Ebreg Ewekewek karya Danarto terjadi ketika Profesor menuduh Slentem dengan sewenang-wenang karena belum disertakan bukti. Pada halaman 8-9 naskah drama tersebut, Profesor menilai Slentem telah menutupi hubungan Tommy dan Kusningtyas tanpa bukti yang jelas. Ny. Profesor telah memberikan pengertian kepada Profesor agar jangan menuduh sebelum melihat sendiri buktinya dan jangan sampai terdengar oleh anaknya.

Kritik sosial masalah kemanusiaan selanjutnya yaitu Profesor tidak berlaku adil terhadap Tommy. Pada halaman 56-57, Sumirah berusaha mencarikan keadilan kepada Tommy dan memberikan pengertian kepada Profesor agar berlaku adil untuk meluluskan Tommy. Sumirah menilai Profesor tidak memberikan penjelasan dan pemberitahuan terlebih dahulu dalam ujian kelulusan. Akan tetapi, jawaban mengejutkan Profesor bahwa dia merupakan seorang profesor lulusan Berkeley University, yang bersih dari segala sentimen-sentimen yang yang dituduhkan. Rasa ketidakadilan juga dirasakan Sumirah untuk memperjuangkan kemanusiaan yang dirasakan Tommy. Kritik sosial mengenai kemanusiaan tersebut menjelaskan bahwa setiap manusia memiliki hak untuk diperlakukan secara adil dan dinilai secara objektif.

Berdasarkan naskah drama Obrog Owokowok Ebreg Ewek-ewek karya Danarto, dapat disimpulkan bahwa terdapat kritik sosial masalah kemanusiaan yaitu tidak memiliki rasa keadilan (sewenang-wenang) dan diskriminasi. Hal tersebut terlihat seperti Profesor menuduh Slentem dengan sewenang-wenang karena belum disertakan bukti, Profesor semena-mena dan seenaknya saat ujian kelulusan terhadap Tommy, Profesor ingin memisahkan Tommy dengan Kusningtyas, Profesor tidak berlaku adil terhadap Tommy, Ny. Profesor juga merasakan ketidakadilan yang dilakukan suaminya terhadap Tommy, alasan Profesor tidak meluluskan Tommy yang tidak masuk akal, dan rasa ketidakadilan yang juga dirasakan Slentem karena Profesor tidak meluluskan Tommy dengan mengirim surat kaleng.

Kritik Sosial Masalah Agama dan Kepercayaan Kritik sosial masalah agama dan kepercayaan dalam teks naskah drama Obrog Owok-owok Ebreg Ewek-ewek karya Danarto terjadi ketika Profesor percaya terhadap Slentem (mengaku dukun) daripada terhadap Tuhan. Pada halaman 43-44 naskah drama tersebut, Profesor percaya terhadap Slentem (mengaku dukun) daripada terhadap Tuhan. Sumirah juga percaya terhadap rambut pemberian Slentem (mengaku dukun) daripada terhadap Tuhan, hal tersebut terdapat pada halaman 46-48. Kemudian pada halaman 63-64 menunjukkan bahwa khasiat rambut yang diberikan Slentem benar-benar dirasakan Profesor dan Sumirah.

\section{Kritik Sosial Masalah Pendidikan}

Kritik sosial masalah pendidikan dalam naskah drama Obrog Owok-owok Ebreg Ewekewek karya Danarto yaitu pada halaman 4. Profesor khawatir proses pembelajaran mahasiswanya pindah ke pasar Beringharjo. Hal tersebut menunjukkan bahwa kualitas pendidikan di luar sekolah lebih baik dan lebih efektif. Pendidik dan pemerintah harus lebih memperhatikan kualitas pendidikan dan mengatasi permasalahan tersebut.

Berdasarkan naskah drama Obrog Owokowok Ebreg Ewek-ewek karya Danarto, dapat disimpulkan bahwa terdapat kritik sosial masalah pendidikan yaitu kualitas pendidikan yang kurang, tidak mau mendengarkan kritikan demi kemajuan, dan pendidikan tinggi demi sebuah titel. Seperti Profesor khawatir proses pembelajaran mahasiswanya pindah ke pasar Beringharjo, Tommy tidak mau mendengar kritikan Profesor demi kemajuan, kritikan pedas Profesor demi kemajuan dan kualitas desain batik Tommy, dan tuntutan mendapatkan titel dalam sebuah pendidikan.

\footnotetext{
Wujud Ekspresi Kritik Sosial Pembangun Estetika dalam Naskah Obrog Owok-Owok Ebreg Ewek-Ewek Karya Danarto
} 
Wujud Ekspresi Kritik Sosial Masalah Ekonomi sebagai Pembangun Estetika Drama

Wujud ekspresi kritik sosial masalah ekonomi dalam naskah drama Obrog Owok-owok Ebreg Ewek-ewek karya Danarto disampaikan melalui dialog-dialog tokoh sebagai cerminan permasalahan ekonomi di masyarakat. Hal tersebut dapat dijadikan sebagai pembangun estetika drama karena bermuara pada nilai ekonomi. Nilai ekonomi adalah salah satu dari macam-macam nilai yang mendasari perbuatan seseorang atau sekelompok orang atas dasar pertimbangan ada tidaknya keuntungan finansial sebagai akibat dari perbuatannya itu.

Wujud Ekspresi Kritik Sosial Masalah Politik sebagai Pembangun Estetika Drama

Dalam naskah drama Obrog Owok-owok Ebreg Ewek-ewek karya Danarto, terdapat wujud ekspresi kritik sosial masalah politik pembangun estetika drama yaitu kritik terhadap pemerintah untuk memperhatikan dan mendukung usaha batik agar berkembang dengan pesat dan mengenai kesejahteraan bagi rakyat kecil seperti pedagang, pengamen, tukang sapu, dan sebagainya. Berdasarkan hal tersebut, kebijakan-kebijakan yang dikeluarkan oleh pemerintah berhubungan langsung dan mempengaruhi kehidupan masyarakat. Hal tersebut tidak jauh berbeda dengan karya sastra yang mencerminkan kehidupan masyarakat.

Wujud Ekspresi Kritik Sosial Masalah SosialBudaya sebagai Pembangun Estetika Drama

Dalam naskah drama Obrog Owok-owok Ebreg Ewek-ewek karya Danarto, terdapat wujud ekspresi kritik sosial masalah sosial-budaya pembangun estetika drama yaitu Sumirah mendesak Slentem untuk mengakui kebenaran mengenai hubungan Tommy dan Kusningtyas demi kebaikan bersama, Ati memberikan pengertian kepada Sumirah mengenai kecurigaan hubungan Tommy dan Kusningtyas, persaingan mengamen antara Sariyem dan Warti, anggapan Sumirah terhadap anggapan titel pendidikan mampu menghasilkan uang untuk kehidupan sosial yang lebih baik, dan penamaan batik oleh Tommy yang kurang sesuai.

\section{Wujud Ekspresi Kritik Sosial Masalah Moral} sebagai Pembangun Estetika Drama

Wujud ekspresi kritik sosial masalah moral sebagai pembangun estetika drama dalam naskah Obrog Owok-owok Ebreg Ewek-ewek karya Danarto yang disampaikan melalui dialogdialog merupakan nilai-nilai yang terkandung di dalam cerita dan berkaitan dengan akhlak atau etika yang berlaku di dalam masyarakat. Nilai moral dalam sebuah karya sastra biasanya di tunjukkan dengan adanya sebuah perilaku dan tutur kata baik yang diperankan oleh tokohnya. Untuk dapat memahami nilai moral itu sendiri, perlu memahami struktur antropologis yang ada dalam diri manusia. Struktur antropologis manusia terdiri atas jasad, ruh, dan akal.

\section{Wujud Ekspresi Kritik Sosial Masalah Kemanusiaan sebagai Pembangun Estetika Drama}

Wujud ekspresi kritik sosial masalah kemanusiaan sebagai pembangun drama dalam naskah Obrog Owok-owok Ebreg Ewek-ewek karya Danarto merujuk pada nilai kemanusiaan. Nilai kemanusiaan yang terdapat dalam naskah drama tersebut mengenai harkat dan martabat manusia dalam masyarakat. Manusia merupakan makhluk tertinggi di antara makhluk ciptaan Tuhan sehingga nilai-nilai kemanusiaan tersebut mencerminkan kedudukan manusia sebagai makhluk tertinggi diantara makhluk-makhluk lainnya. Seseorang mempunyai nilai-nilai kemanusiaan yang tinggi menghendaki masyarakat memiliki sikap dan perilaku sebagai layaknya manusia. Sebaliknya dia tidak menyukai sikap dan perilaku yang sifatnya merendahkan manusia lain.

\section{Wujud Ekspresi Kritik Sosial Masalah Agama dan Kepercayaan sebagai Pembangun Estetika Drama}

Dalam naskah drama Obrog Owok-owok Ebreg Ewek-ewek karya Danarto, terdapat wujud ekspresi kritik sosial masalah agama dan kepercayaan sebagai pembangun estetika drama yaitu Profesor percaya terhadap Slentem (mengaku dukun) daripada terhadap Tuhan, Sumirah juga percaya terhadap rambut pemberian Slentem (mengaku dukun) daripada terhadap Tuhan, dan khasiat rambut yang diberikan Slentem benarbenar dirasakan Profesor dan Sumirah. Hal tersebut menunjukkan bahwa dalam naskah tersebut terdapat nilai agama atau religiusitas berupa pengakuan adanya Tuhan dan kekuasaan Tuhan atas alam semesta ini. Nilai religiusitas tersebut meliputi, percaya kepada Tuhan, percaya pada takdir, suka berdoa, suka bertaubat, bersyukur, dan tabah. Nilai agama dan kepercayaan ini tersampaikan kepada penonton melalui pertunjukan yang menggambarkan tentang kehidupan beragam dan erat hubungannya dengan peningkatan kepercayaan terhadap Tuhan Yang Maha Esa. 
Wujud Ekspresi Kritik Sosial Masalah Pendidikan pebagai Pembangun Estetika Drama

Dalam naskah drama Obrog Owok-owok Ebreg Ewek-ewek karya Danarto, terdapat wujud ekspresi kritik sosial masalah pendidikan pembangun estetika drama yang merujuk pada nilai pendidikan yaitu Profesor khawatir proses pembelajaran mahasiswanya pindah ke pasar Beringharjo, Tommy tidak mau mendengar kritikan Profesor demi kemajuan, kritikan pedas Profesor demi kemajuan dan kualitas desain batik Tommy, dan tuntutan mendapatkan titel dalam sebuah pendidikan.

\section{PENUTUP}

Dari penelitian tentang kritik sosial dan nilai-nilai kritik sosial tersebut membangun estetika drama dalam naskah Obrog Owok-owok Ebreg Ewek-ewek karya Danarto, penulis memperoleh kesimpulan sebagai berikut: 1. Kritik sosial yang terdapat dalam naskah drama Obrog Owok-owok Ebreg Ewek-ewek karya Danarto yaitu: a) Kritik sosial masalah ekonomi mengenai penilaian ekonomi yang tidak sebanding dengan kreativitas, pengeluaran kebutuhan ekonomi yang tidak sebanding dengan pendapatan, dan keuntungan ekonomi para pelaku usaha. b) Kritik sosial masalah politik yaitu kritik terhadap pemerintahan mengenai kesejahteraan masyarakat. c) Kritik sosial masalah sosial-budaya mengenai menjaga solidaritas demi terciptanya kehidupan yang damai, anggapan gelar demi kehidupan sosial yang lebih baik, dan penamaan batik oleh Tommy yang kurang sesuai. d) Kritik sosial masalah moral yaitu menuduh sesorang tanpa disetai bukti, menebar ancaman terhadap seseorang, berperilaku sombong, menyimpan dendam, selalu menebar janji, berkata kasar, menipu, dan tidak jujur. e) Kritik sosial masalah kemanusiaan yaitu tidak memiliki rasa keadilan (sewenang-wenang) dan diskriminasi. f) Kritik sosial masalah agama dan kepercayaan mengenai lebih percaya terhadap seseorang atau benda daripada Tuhan. g) Kritik sosial masalah pendidikan mengenai kualitas pendidikan yang kurang, tidak mau mendengarkan kritikan demi kemajuan, dan pendidikan tinggi demi sebuah gelar. 2. Wujud ekspresi kritik sosial pembangun estetika drama dalam Obrog Owokowok Ebreg Ewek-ewek karya Danarto, yaitu: a) Wujud ekspresi kritik sosial masalah ekonomi sebagai pembangun estetika drama yaitu bertumpu pada nilai ekonomi, karena salah satu dari macammacam nilai yang mendasari perbuatan seseorang atau sekelompok orang atas dasar pertimbangan ada tidaknya keuntungan finansial sebagai akibat dari perbuatannya. b) Wujud ekspresi kritik sosial masalah politik sebagai pembangun estetika drama yaitu kritik terhadap pemerintah agar memperhatikan dan mendukung usaha batik dapat berkembang dengan pesat dan mengenai kesejahteraan bagi rakyat kecil. c) Wujud ekspresi kritik sosial masalah sosial-budaya sebagai pembangun estetika drama merupakan acuan dalam kehidupan masyarakat untuk menentukan sesuatu itu dikatakan baik atau buruk, pantas atau tidak pantas untuk dilakukan masyarakat. d) Wujud ekspresi kritik sosial masalah moral sebagai pembangun estetika drama merupakan nilai-nilai yang terkandung di dalam cerita dan berkaitan dengan akhlak atau etika yang berlaku di dalam masyarakat. e) Wujud ekspresi kritik sosial masalah kemanusiaan sebagai pembangun estetika drama merupakan nilai mengenai harkat dan martabat manusia dalam sebuah pemenatasan. f) Wujud ekspresi kritik sosial masalah agama dan kepercayaan sebagai pembangun estetika drama berupa pengakuan adanya Tuhan dan kekuasaan Tuhan atas alam semesta ini. g) Wujud ekspresi kritik sosial masalah pendidikan sebagai pembangun estetika drama mampu memberikan edukasi terhadap penonton atau penikmat karya sastra.

Dari penelitian tentang naskah drama Obrog Owok-owok Ebreg Ewek-ewek karya Danarto, penulis memberi saran kepada pembaca sebagai berikut: hasil penelitian sosiologi sastra diharapkan dapat menambah khazanah penelitian sastra dan dapat menjadi referensi penelitian sastra berikutnya yang menggunakan pendekatan sosiologi sastra dengan memfokuskan peneltitian pada naskah drama. Dalam penelitian ini belum menyertakan pembahasan tentang petunjuk laku atau lakuan tokoh sebagai simbol kritik sosial, harapannya hal tersebut dapat diteliti oleh peneliti lain. Selain itu, bagi peneliti yang hendak menggunakan naskah drama Obrog Owok-owok Ebreg Ewek-ewek karya Danarto sebagai objek penelitian, diharapkan dapat mengembangkan lebih lanjut dengan menggunakan pendekatanpendekatan lain, seperti pendekatan psikologi sastra, pendekatan struktural, semiotik, ataupun pendekatan lain, karena naskah drama tersebut menarik untuk djadikan objek penelitian.

\section{DAFTAR PUSTAKA}

Damono, Sapardi Djoko. 1984. Sosiologi Sastra: Sebuah Pengantar Ringkas. Jakarta: Pusat Pembinaan dan Pengembangan Bahasa.

Djelantik, A.A.M. 2004. Estetika: Sebuah Pengantar. Bandung: Masyarakat Seni Pertunjukan Indonesia. 
Dewojati, Cahyaningrum. 2012. Drama: Sejarah, Teori, dan Penerapannya. Yogyakarta: Javakarsa Media.

Faruk. 1999. Pengantar Sosiologi Sastra (Dari Strukturalisme Genetik sampai Post Modernisme). Yogyakarta: Pustaka Pelajar.

Harrymawan, R.M.A.. 1988. Dramaturgi. Bandung: Rosda.

Hasanuddin. 1996. Drama (Karya dalam Dua Dimensi). Bandung: Angkasa Bandung.

Ratna, Nyoman Kutha. 2009. Stilistika : Kajian Puitika Bahasa, Sastra, dan Budaya. Yogyakarta: Pustaka Pelajar.

Sikana, Mana. 2006. Kritikan Sastra Melayu Modern. Singapura: Pustaka Karya.

Sugiarti. 1999. Kajian Kontemporer Ilmu Budaya Dasar. Malang: UMM Press. 